\title{
Byler-like familial cholestasis in an extended kindred
}

\section{Department of Paediatrics, University College Dublin, Republic of Ireland B Bourke N Goggin D Walsh \\ B Drumm \\ Department of Pathology, St Vincent's Hospital, Dublin, Republic of Ireland $S$ Kennedy \\ Clinical Mass Spectrometry Center, Children's Hospital Medical Center, Cincinnati, Ohio, USA K D R Setchell \\ Correspondence to: Dr Billy Bourke, Division of Gastroenterology, Hospital for Sick Children, 555 University Avenue, Toronto, Ontario, Canada M5G 1 X8.}

Accepted 29 April 1996

\begin{abstract}
Progressive familial intrahepatic cholestasis (PFIC) occurs in many communities and races. A form of PFIC in five children from two consanguineous marriages in an Irish kindred is described. In addition, a review of clinical information from the records of three deceased members of the kindred strongly implies that they also suffered from PFIC. The children had a history of neonatal diarrhoea, sepsis, and intermittent jaundice that ultimately became permanent. They suffered intractable pruritus and growth retardation. Despite evidence of severe cholestasis, serum $\gamma$-glutamyl transferase and cholesterol were normal in these children. Sweat sodium concentration were raised in three children. Liver histology showed severe intrahepatic cholestasis and hepatocellular injury. Urinary bile acid analysis revealed a non-specific pattern consistent with chronic cholestasis. These children suffer from a form of PFIC remarkably similar to that occurring in members of the Byler kindred.

(Arch Dis Child 1996;75:223-227)
\end{abstract}

Keywords: familial cholestasis, Byler disease.

In 1969 Clayton et al described seven members of an Amish family descended from Jacob Byler with progressive familial intrahepatic cholestasis (PFIC). ${ }^{1}$ Although there have been reports of a similar disease occurring in various individuals and, races ${ }^{2-1011-12}$ many of these patients differed clinically from the Byler children. Therefore, it is recognised that PFIC comprises a heterogenous group of conditions. ${ }^{13}$ We describe eight affected children from a single kindred with a form of familial intrahepatic cholestasis very similar to that of the original Byler family. This kindred is part of a group of highly intermarried (fig 1) Irish travellers (an indigenous Irish nomadic community). Familial cholestasis affecting eight related children offered a unique opportunity for a detailed clinical and pathological study of the natural history of this rare disease.

\section{Patients}

Clinical and biochemical profiles for the five members of the kindred reviewed in this hospital were obtained from other hospital records and appear in tables 1 and 2. Before cholestasis became clinically apparent these children suffered from episodes of sepsis and severe, protracted diarrhoea. These features continued after cholestasis was established and caused significant morbidity throughout early childhood years.

In three of the children, episodic jaundice appeared within the first two months of life. However, the onset of jaundice was delayed until 6 and 9 months respectively in the other two children.

For each of the children, the established illness was dominated by the complications of chronic cholestasis. Severe, intractable pruritus that was unresponsive to trials of phenobarbitone,rifampicin, ursodeoxycholicacid, or phototherapy was a particularly distressing symptom. Marked hepatosplenomegaly was present in all children. The liver was palpable between 4 and $10 \mathrm{~cm}$ below the right costal margin and spleens were palpable up to $4 \mathrm{~cm}$ below the left costal margin. In all cases the liver was of very firm consistency. Short stature and failure to thrive were also prominent (table 1).

Recurrent epistaxis was common to all five children. However, haematemesis occurred in only one child. Intellectual development was normal in all of these children.

A number of additional features were also present. Each of the five living children had fine hypopigmented hair. These children also manifested a spectrum of dystrophic nail changes. Mild fingernail pitting, which was evident in the younger children, was superceded by gross dystrophic changes in the older two. Nail scrapings taken from the eldest child grew Candida inconspicua.

\section{Results}

Varying degrees of conjugated hyperbilirubinaemia and liver enzyme elevation were present (table 2). However, in all of the children, serum albumin and prothrombin time were normal, suggesting hepatic synthetic function was relatively preserved. During intercurrent illness liver enzyme values increased markedly. $\gamma$-Glutamyl transferase and cholesterol were normal or near normal in all five children studied. All of the children had markedly raised faecal fat content and severe fat soluble vitamin deficiency.

Abnormal sweat tests were documented in three of these children (table 2). Results of sweat tests performed during infancy were available for four living children (patients 1,3 , 4 , and 5) and for two of the children now dead. These sweat tests were all in the normal range during infancy. In view of the abnormal sweat 
Table 1 Clinical findings in (living) members of kindred with Byler disease

\begin{tabular}{lllllllll}
\hline Patient No & Age (years) & $\begin{array}{c}\text { Onset of } \\
\text { jaundice } \\
\text { (months) }\end{array}$ & Height centile & Weight centile & $\begin{array}{l}\text { Pruritus } \\
\text { (0-4 + *) }\end{array}$ & $\begin{array}{l}\text { Nail } \\
\text { dystrophy }\end{array}$ & $\begin{array}{l}\text { Hepatomegaly } \\
\text { (cmf) }\end{array}$ & Haematemesis \\
\hline 1 & 12 & 6 & $<3$ & $<3$ & $3-4+$ & Severe & $6-8$ & Yes \\
2 & 11 & $<2$ & $<3$ & $<3$ & $2-3+$ & Moderate & $8-9$ & No \\
3 & 6 & $<2$ & $<3$ & $<3$ & $3+$ & Mild & 9 & No \\
4 & 4 & 9 & $<3$ & 3 & $3-4+$ & Mild & $7-8$ & No \\
5 & 4 & $<2$ & $<3$ & $<3$ & $3+$ & Mild & 4 & No \\
\hline
\end{tabular}

* Pruritus scoring: $0=$ none, $1+=$ rubbing or scratching when undistracted, $2+=$ scratching without abrasions, $3+=$ abrasions evident, $4+=$ cutaneous mutilation, haemorrhage, and scarring.

† Measurements indicate liver size below the right costal margin.

Table 2 Biochemical findings in (living) members of kindred with Byler disease

\begin{tabular}{|c|c|c|c|c|c|c|c|c|c|c|c|}
\hline \multirow[b]{2}{*}{$\begin{array}{l}\text { Patient } \\
\text { No }\end{array}$} & \multirow[b]{2}{*}{$\begin{array}{l}\text { Age } \\
\text { (years) }\end{array}$} & \multirow[b]{2}{*}{$\begin{array}{l}A S T \\
(I U / l)\end{array}$} & \multirow[b]{2}{*}{$\begin{array}{l}A L P \\
(I U / l)\end{array}$} & \multirow[b]{2}{*}{ 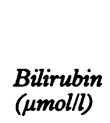 } & \multirow{2}{*}{\multicolumn{2}{|c|}{$\begin{array}{l}\text { Cholesterol Albumin } \\
\text { (mmol/l) (g/l) }\end{array}$}} & \multirow[b]{2}{*}{$\begin{array}{l}\text { Prothrombin } \\
\text { time }(s)\end{array}$} & \multirow[b]{2}{*}{$\begin{array}{l}G G T \\
(I U / l)\end{array}$} & \multirow[b]{2}{*}{$\begin{array}{l}\text { 5'NT } \\
\text { (IU/l) }\end{array}$} & \multicolumn{2}{|l|}{ Sweat } \\
\hline & & & & & & & & & & $\begin{array}{l}\text { Sodium } \\
\text { (mmolll) }\end{array}$ & $\begin{array}{l}\text { Chloride } \\
\text { (mmolll) }\end{array}$ \\
\hline 1 & 12 & 45 & 508 & 170 & 3.5 & 39 & 15 & 20 & 25 & 50 & 33 \\
\hline 2 & 11 & 62 & 723 & 86 & 4.6 & 40 & 13 & 21 & 35 & 30 & 17 \\
\hline 3 & 6 & 75 & 908 & 183 & 5.9 & 43 & 12 & 22 & 42 & 102 & 79 \\
\hline 4 & 4 & 56 & 536 & 45 & 4.3 & 40 & 12 & 19 & 16 & 88 & 69 \\
\hline 5 & 4 & 111 & 750 & 172 & 3.7 & 42 & 13 & 46 & 33 & 28 & 25 \\
\hline $\begin{array}{l}\text { Normal } \\
\text { values }\end{array}$ & - & $8-40$ & - & $<17$ & $2.3-5$ & $33-58$ & $10.5-15$ & $<24$ & $<12$ & $<40$ & $<40$ \\
\hline
\end{tabular}

Biochemical parameters refer to values at presentation to this hospital (at age as given). AST = aspartate aminotransferase; ALP = alkaline phosphatase; GGT = $\gamma$-glutamyltransferase; 5'NT = 5'-nucleotidase.

tests the four siblings, patients $1,2,3$, and 4, and their mother were all screened for cystic fibrosis $\Delta \mathrm{F} 508$ mutation and 10 other mutations common among Irish cystic fibrosis patients including $\mathrm{R} 117 \mathrm{H}, \mathrm{DI507}, \mathrm{G} 542 \mathrm{X}$, G551D, R560T/R560K, N1303K, W1282X, $R 553 X, 1717-1 G \rightarrow A$ and $621+1 G \rightarrow T$. Each of the children and their mother were negative for all 11 mutations.

Exhaustive investigations were undertaken to rule out other causes of cholestasis. Screening studies for hepatitis $A, B$, and $C$ were negative. Serum and urinary amino acid chromatography and urinary organic acid profile gave normal reults. The serum $\alpha_{1}$-antitrypsin values and phenotype were also normal. Extrahepatic
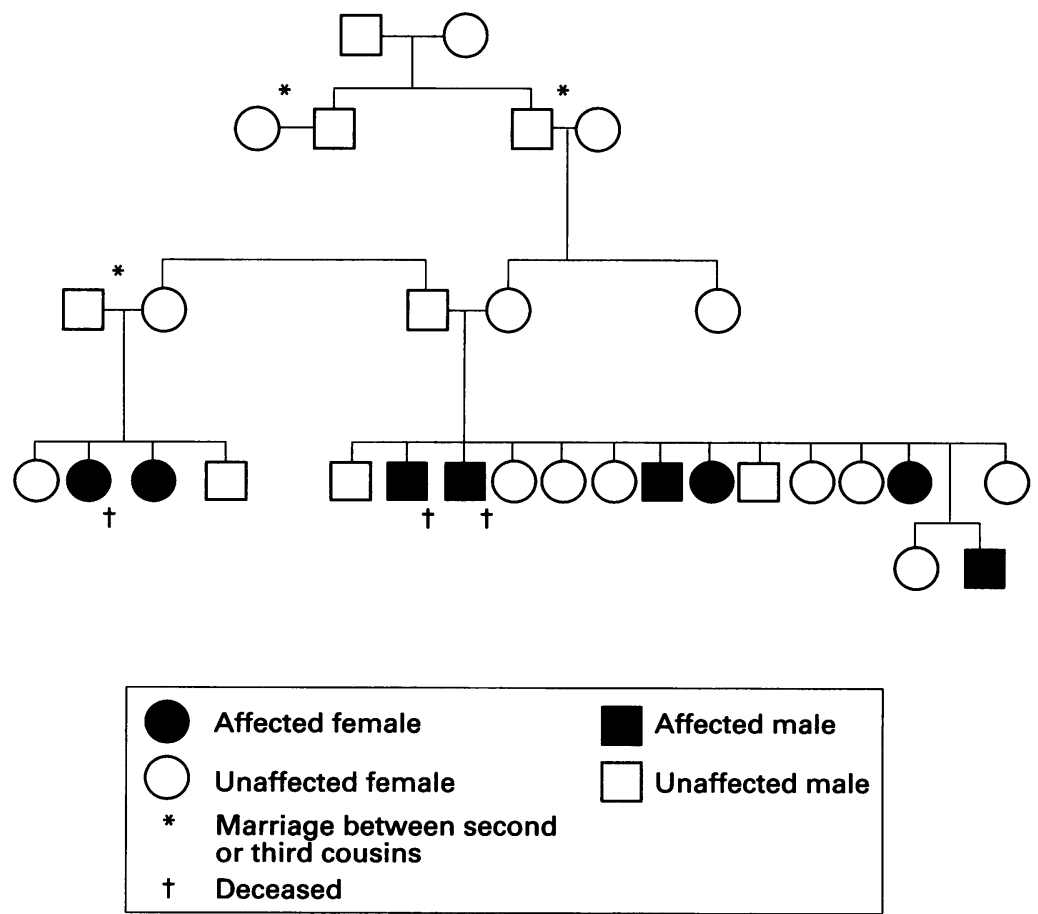

Figure 1 Pedigree of Irish Byler kindred illustrating high degree of intermarriage. manifestations of Alagille's syndrome, such as posterior embryotoxin and butterfly vertebrae, were sought but not found. Karyotype was normal in all of the children.

Three other children from this kindred died from sepsis. Two children were aged 4 months and one was 15 months. Clinical information was available for two of these children. The 15 month old child was diagnosed in another hospital with PFIC. She had recurrent diarrhoea and failure to thrive before the onset of jaundice and pruritus at age 7 months. Her disease was clinically and biochemically identical to that of the five living children described above. The 4 month old child suffered with severe diarrhoea and failure to thrive from age 1 month. At the time of death (4 months) he was anicteric but had markedly raised transaminases (alanine aminotransferase $=468$ $\mathrm{U} / \mathrm{l})$. No clinical notes were available for the third child. However, he was jaundiced at the time of death.

Each of the five living children were followed up at this institution for three years since the initial referral; they were maintained on fat soluble vitamin replacements. The eldest child required intermittent hospitalisations during intercurrent infections, which were commonly accompanied by bouts of watery diarrhoea. Although copious, stool output diminished appropriately during fasting. Invariably, pathogenic organisms were absent from stools during these episodes. Furthermore, immunological investigations performed on a subgroup of these children including immunoglobulin concentrations (patients 1 and 3 ) and $T$ cell subsets (patient 1) were normal. IgG $1, \mathrm{IgG}_{2}$, and $\mathrm{IgG}_{4}$ subclasses were raised in the one child (patient 3 ) in whom they were evaluated. Despite the severity of cholestasis during this period there was no clinical or biochemical evidence of disease progression among any of the children. 
LIVER HISTOLOGY

Liver biopsy specimens were obtained from each of these children. The specimens from the youngest children (patients 3, 4, and 5) showed moderate periportal inflammation and portal expansion. In these specimens there was apparently normal bile duct number and calibre with neocholangiole formation at the periphery of the portal tracts. Changes within the lobular parenchyma included pseudorosette or pseudoacinar formation with bile thrombi and canalicular bile stasis (fig $2 \mathrm{~A}$ ). In the specimens from the older children (patients 1 and 2), pseudoacinar change and cholangiolar bile stasis were equally prominent with giant cell transformation in the children aged 11 and 12 years (fig 2B). Steatosis was not seen. Thin fibrous bands extended out from the portal tracts in these specimens, although bridging fibrosis and regenerative nodules were not present (fig $2 \mathrm{C}$ ). In specimens from these older children there were inflammatory aggregates within the hepatic parenchyma and occasional acidophil bodies. Hepatocellular architectural changes such as irregular liver cell plates were seen at this stage. An acquired paucity of intralobular bile ducts was also present in these specimens.

URINARY BILE ACID ANALYSIS

Urinary bile acids were analysed for four of the children (patients 1,2,3, and 4). Bile acids were extracted, concentrated, and analysed by fast atom bombardment ionisation-mass spectrometry (FAB-MS) and gas chromatographymass spectrometry (GC-MS). ${ }^{14-16}$ The results of FAB-MS and GC-MS analysis revealed similar patterns for each of the four children. All children were capable of synthesising the two primary bile acids. Each had markedly increased total urinary bile acid excretion. Raised excretion of glycine, taurine, and sulphate conjugates of dihydroxy, trihydroxy, and tetrahydroxy cholanoic acids was detected. The pattern of bile acid excretion was consistent with chronic cholestasis rather than an inborn error of bile acid synthesis.

\section{Discussion}

Since the report of Clayton et al in $1969,{ }^{1}$ the terms PFIC and Byler disease have been used synonymously for this condition. However, it is clear that many cases described subsequently demonstrate considerable clinical, biochemical, and pathological heterogeneity. ${ }^{2-4} 611$ Therefore, it is now speculated that PFIC includes a group of conditions of varying aetiologies. ${ }^{12}$ In this report we have described a form of PFIC affecting an extended kindred of Irish travellers.

Members of this kindred suffered with a form of PFIC identical in many respects to that of the Byler kindred. Specific features common to this Irish family and the original Byler kindred include early onset of diarrhoea followed by episodic cholestatic jaundice, which ultimately becomes permanent, intractable pruritus, growth, but not mental, retardation, fine blond hair, the complications of fat soluble vitamin deficiency, normal serum cholesterol, and recessive inheritance pattern. ${ }^{17}$ It is also noteworthy that a high degree of intermarriage is common among both the Amish and Irish travelling people. However, some features specific to the children in this report (for example nail dystrophy) suggest that this Irish family may suffer from a unique form of PFIC.

Death in early life is a feature among some children with this condition. ${ }^{18}{ }^{17}$ Three children in this kindred are dead, two in infancy and one at 15 months old. Of the five living children, all spent the greater part of the first year of life in hospital. True Byler disease and Byler-like familial cholestasis associated with low serum $\gamma$-glutamyltransferase is associated with a poor prognosis. ${ }^{18}$ However, it is noteworthy that survival past infancy in this Irish kindred has been followed by relatively slow disease progression, albeit in the face of severe cholestasis and a high level of morbidity.
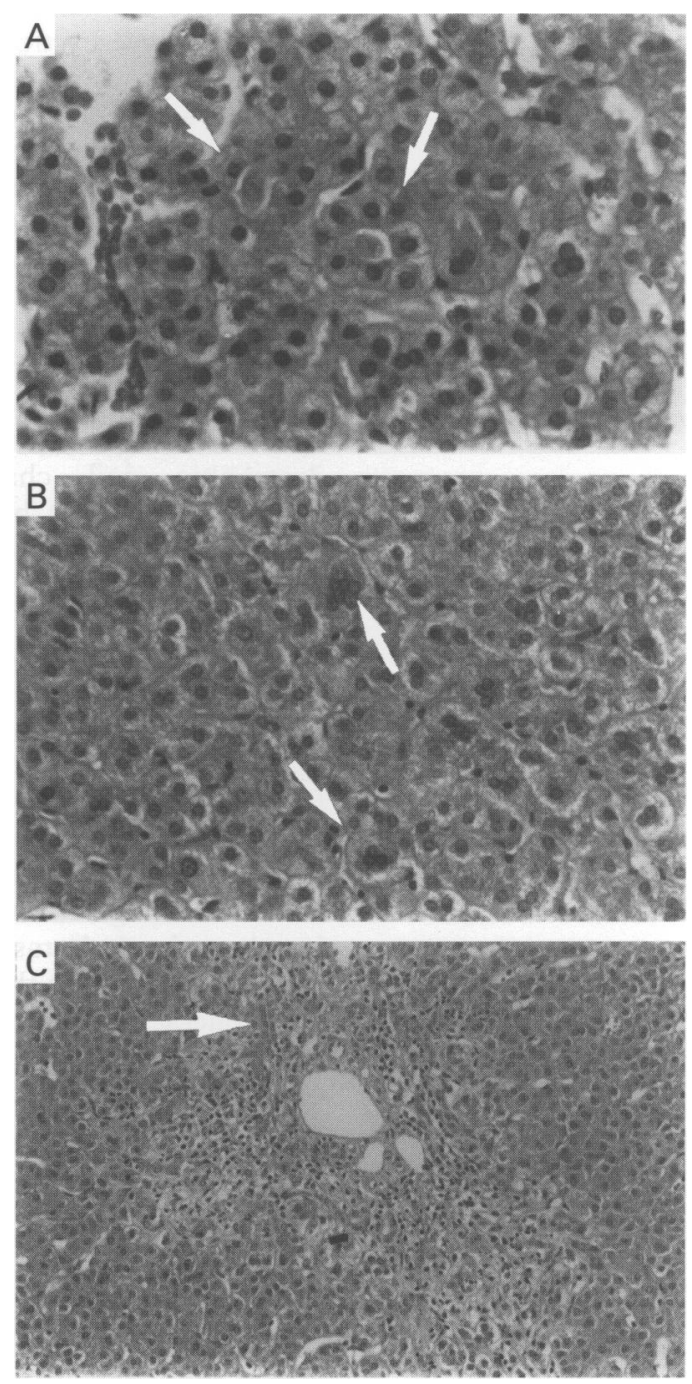

Figure 2 Liver biopsy specimens. (A) Biopsy specimen taken from patient 4 (aged 4 years). Pseudoacinar transformation (arrows) and intracanalicular bile are prominent (magnification $\times 200)$. (B) Biopsy specimen taken from patient 1 (aged 12 years); there is hepatocellular disarray with multinucleate hepatocytes scattered

throughout the liver parenchyma (arrows) (magnification $\times 200)$. (C) Biopsy specimen from patient 1 ; there is stellate periportal fibrosis and inflammation spilling into the adjacent hepatic parenchyma. Transformation of hepatocytes to neocholangioles can be seen at the edges of the portal tracts (arrows) (magnification $\times 100$ ). 
Recurrent diarrhoea and sepsis were features of this disease in the original Byler kindred. A recent report from Switzerland describes a similar case presenting with idiopathic diarrhoea and recurrent sepsis. ${ }^{8}$ Although we are not told of any relationship between this case and the Byler family, it is of interest that the Byler kindred were of Swiss descent. ${ }^{17}$

Sweat electrolytes are reported to be raised in some children with PFIC. ${ }^{19}{ }^{20}$ In this study, raised or high normal sweat sodium values were observed in all except one child (patient 5) over 6 months old. Frankly raised sweat sodium was found in three children aged 4,6 , and 12 years. Normal sweat test results were documented elsewhere for five of these children during infancy. This suggests that sweat sodium is normal in early life when diagnostic confusion with cystic fibrosis would be most likely to occur. Conversely raised sweat sodium or chloride may be a useful marker for this condition in later childhood. Despite some phenotypic similarities these children do not appear to have cystic fibrosis as they have no evidence of respiratory disease and do not manifest any of the more common cystic fibrosis mutations found in the Irish population. In addition, the immune reactive trypsinogen value was not depressed in one child (patient 3 ) in whom it was measured, consistent with intact pancreatic function.

Cell mediated immunity has been documented to be abnormal in patients with PFIC, ${ }^{21}$ which may account for the recurrent episodes of sepsis in these children. Although dystrophic nail changes associated with chronic candidiasis have not previously been reported in PFIC, nail channel osteomyelitis occurred in a very similar case. ${ }^{8}$ Although we failed to observe an abnormality in immunoglobulin concentrations or $\mathrm{T}$ cell subsets in members of this family, chronic nail infection offers further evidence for a defect in cell mediated immunity in PFIC. The relevence of the observed increase in IgG sublasses in one of the kindred is as yet uncertain.

In this series the liver disease is characterised at the histological level by a combination of intrahepatic cholestasis and hepatocellular injury consistent with the toxic affect of accumulated bile acids. Giant cell transformation was not remarkable in the biopsy specimens of the original Byler kindred. ${ }^{17}$ However, giant cell transformation has been commented on in other cases of PFIC, ${ }^{22}$ including a case typical of the original family in other respects. ${ }^{8}$ Pseudoacini or rosettes are a prominent feature of the disease in most reports. Paucity of bile ducts has been a prominent feature in some reports of PFIC. ${ }^{32}$ Ductular proliferation rather than paucity was present in the early infancy biopsy specimens in the original report of this condition. ${ }^{1}$ However, ductular paucity (with focal ductular proliferation) was present in a child aged 3.5 with the typical disease. ${ }^{8}$

There is considerable disagreement about the typical pattern of bile acid excretion in PFIC. ${ }^{12517}$ However, there is no evidence to implicate an inborn error of bile acid synthesis as a cause of this disease. We found no evidence to suggest a primary defect in bile acid synthesis in this family. We were also unable to detect a raised cholic acid to chenodeoxycholic acid ratio in urine from this family with PFIC as has been described for other patients with PFIC. ${ }^{9}$ A recent report from France implicates a defect in canalicular secretion of bile acids in the aetiology of PFIC. ${ }^{23}$ This assumption was based on the finding of very low concentration of biliary bile acids in the presence of raised serum bile acids coupled with normal serum $\gamma$-glutamyltransferase in seven unrelated children with PFIC. Further studies comparing the bile acid profiles of urine, serum, and bile from patients of the original Byler kindred and others displaying a similar disease (such as those described in this report) will help confirm this finding. Such studies would also help to more precisely establish the relationship of Byler disease to other forms of PFIC.

Although not phenotypically identical, this extended non-Amish family suffers from a form of PFIC remarkably similar to that of the Byler kindred. An understanding of these rare diseases may provide insights into the aetiopathogenic events underlying more frequently encountered cholestatic conditions such as that associated with cystic fibrosis. Therefore, further investigations are warranted to elucidate the aetiology of these conditions.

We thank Dr J Murphy, Dr M Taylor, and Dr E Naughten for allowing us the opportunity to examine these patients. We are grateful to Dr S McQuaid and Dr D Barton for providing molecular genetic analysis and Dr Bernard Portmann for additional histopathological consultations during the management of these children.

1 Clayton RJ, Iber FL, Ruebner BH, McKusick VA. Byler disease. Fatal familial intrahepatic cholestasis in an Amish kindred. $A m$ F Dis Child 1969; 117: 112-24.

2 Williams CN, Kaye R, Baker L, Hurwitz R, Senior JR. Progressive familial cholestatic cirrhosis and bile acid metabolism. $\mathcal{F}$ Pediatr 1972; 81: 493-500.

3 Ballow M, Margolis CZ, Schachtel B, Hsia YE. Progressive familial intrahepatic cholestasis. Pediatrics 1973; 51: 998-1007.

4 Odievre M, Gautier M, Hadchouel M, Alagille D. Severe familial intrahepatic cholestasis. Arch Dis Child 1973; 48: familial

5 De Vos R, De Wolf-Peeters C, Desmet V, Eggermont E, Van Acker K. Progressive intrahepatic cholestasis (Byler's disease): case report. Gut 1975; 16: 943-50.

6 Jones EA, Rabin L, Buckley CH, Webster GK, Owens D. Progressive intrahepatic cholestasis of infancy and childhood. Gastroenterology 1976; 71: 675-82.

7 Nakagawa M, Tazawa Y, Kobayashi Y, et al. Familial intrahepatic cholestasis associated with progressive neuromuscular disease and vitamin $\mathrm{E}$ deficiency. $₹$ Pediatr Gastroenterol Nutr 1984; 3: 385-9.

8 Winklhofer-Roob BM, Shmerling DH, Solèr R, Briner J. Progressive idiopathic cholestasis presenting with profuse watery diarrhoea and recurrent infections (Byler's disease). Acta Paediatr 1992; 81: 637-40.

9 Whitington PF, Freese DK, Alonso EM, Fishbein MH, Emond JC. Progressive familial intrahepatic cholestasis Emond JC. Progressive familial intrahepatic cholestasis
(Byler's disease). In: Lentze M, Reichen J, eds. Paediatric cholestasis-novel approaches to treatment. Dordrecht: Kluwer cholestasis-novel approaches to treatment.

10 Gray OP, Saunders RA. Familial intrahepatic cholestatic jaundice in infancy. Arch Dis Child 1966; 41: 320-8.

11 Dahms BB. Hepatoma in familial cholestatic cirrhosis of childhood. Arch Pathol Lab Med 1979; 103: 30-3.

12 Riely CA. Familial intrahepatic cholestasis: an overview. In: Walker WA, Durie PR, Hamilton JR, Walker-Smith JA, Watkins JB, eds. Pediatric gastrointestinal disease. Vol 2. Philadelphia: BC Decker, 1991:1025-32.

13 Whitington PF, Freese DK, Alonso EM, Schwarzenberg SI, Sharp HL. Clinical and biochemical findings in progressive familial intrahepatic cholestasis. $\mathcal{F}$ Pediatr Gastroenterol Nutr 1994; 18: 134-41.

14 Setchell KDR, Worthington J. A rapid method for the quantitative extraction of bile acids and their conjugates from serum using commercially available reverse phase octadecylsilane bonded silica cartridges. Clin Chim Acta 1982; 125: 135-44. 
15 Sjovall J, Lawson AM, Setchell KDR. Mass spectrometry of bile acids. In: Law JH, Rilling HC, eds. Methods and enzymology. Vol 1. London: Academic Press, 1985:63-113.

16 Setchell KDR, Matsui A. Serum bile acid analysis: the application of liquid-gel chromatographic techniques and application of liquid-gel chromatographic techniques and
capillary column gas chromatography and mass spectromcapillary column gas chromatography
etry. Clin Chim Acta 1983; 127: 1-17.

17 Linarelli LG, Williams CN, Philips MJ. Byler's disease: fatal Linarelli LG, Williams CN, Philips MJ. Byler's disease:

18 Maggiore G, Bernard O, Riely C, Hadchouel M, Lemonnier A, Alagille D. Normal serum $\gamma$-glutamyl-transpeptidase activity identifies groups of infants with idiopathic cholestasis with poor prognosis. $\mathcal{F}$ Pediatr $1987 ; 113$ : 251-2. 19 Hillemeier AC, Hen J, Riely CA, Dolan TF, Gryboski JD. Meconium peritonitis and increasing sweat chloride determinations in a case of familial progressive intrahepatic cholestasis. Pediatrics 1982; 69: 325-7.
20 Lloyd-Still JD. Familial cholestatic syndrome with elevated sweat electrolytes. In: Sturgess JM, ed. Proceedings of the 8th International Congress on Cystic Fibrosis. Toronto: Imperial Press, 1980:25a.

21 Maggiore G, De Giacomo C, Scotta MS, Siena S, Maccario Maggiore G, De Giacomo C, Scotta MS, Siena S, Maccario
R, Vitiello A. Cell-mediated immunity in children with chronic cholestasis. F Pediatr Gastroenterol Nutr 1982; 1: 385-8.

22 Alonso EM, Snover DC, Montag A, Freese DK, Whitington PF. Histologic pathology of the liver in progressive familial intrahepatic cholestasis. F Pediatr Gastroenterol Nutr 1994; 18: 128-33.

23 Jacquemin E, Dumont M, Bernard O, Erlinger S, Hadchouel $M$. Evidence for defective primary bile acid secretion in children with progressive familial intrahepatic cholestasis. Eur $\mathcal{F}$ Pediatr 1994; 153: 424-8. 
ing theme: bronchiolitis, cystic fibrosis and bronchopulmonary dysplasia, among others, are listed together as causes of wheezing but would rarely be considered together as possible diagnoses.

In the text I would have welcomed more emphasis on differential diagnosis and more information about the relative incidence of the conditions mentioned under each heading. There are some excellent concise accounts. These are particularly useful where information in textbooks is lacking, for example Munchausen disease by proxy, and where an overview directs further reading, for example headaches and convulsions. However, combining an attempt to say something about every condition with a need for brevity often results in simplistic accounts, for example, 'Crohn's disease is a rare though important cause of abdominal pain in childhood'.

This book, despite its limitations, usefully supplements standard texts. Paediatricians may be helped when encountering less common symptoms and signs and when there is a need to consider the rarer causes of common symptoms. I have found it helpful when considering the differential diagnosis of such diverse symptoms and signs as livedo reticularis, excessive sweating, and the rarer causes of apnoea in infancy. The enthusiastic student may also usefully refer to the book when starting to face diagnostic dilemmas.

CAROLYN J ADCOCK Senior registrar

Paediatric Pathology. 3rd Ed. Edited by Sir Colin Berry. (Pp 942; £195 hardback.) Springer-Verlag, 1996. ISBN 3-54019936-5.

Professor Berry's Paediatric Pathology now enters its third edition, only six years after its second. Over the three editions the size has increased significantly with a smaller text size on more pages. As a paediatric book, it largely avoids those diseases and conditions associated more with the process of birth or prematurity, although of course congenital malformation features large. While some overlap is inevitable, it is a stablemate of, and largely complementary to, Keeling's Fetal and Neonatal Pathology. The book is directed primarily towards the general rather than the specialist paediatric pathologist and, as there is no direct competition in paediatric pathology, should find a receptive audience.

As a paediatric pathologist, I have found previous editions a little too thin to be of very much practical help when faced with a probem. Exception are those chapters that describe a very practical approach to a problem whether of description (cardiac) or of specimen handling and diagnostic requirements (metabolic).

If described at all, conditions have been covered too briefly with little discussion of differential diagnosis. As I doubt a general pathologist will need less information and explanation to understand a problem than a specialist, I suspect my experience is true for the target readership.

But that is the past, what of the third edition? There is no significant change to the overall format. As before, chapters cover organ and system pathology in a conventiona manner but also with chapters on sudden unexpected infant death, embryonal tumours, and theoretical aspects of congenital malformation. There are some changes in authorship and new chapters on the pathology of AIDS and bone marrow pathology. The text is well set out and the illustrations generally of good quality.

However, the most significant alteration since the first edition is a cumulative one. The modification of chapter titles together with a gradual expansion of some chapter lengths, not necessarily extensive, has led to a text that will be a better resource to general and specialist pathologists needing an introduction to less familiar areas. It may be premature to look forward to the fourth edition, but I hope this trend towards expansion continues.

STEVEN GOULD Consultant paediatric pathologist

Gellis and Kagan's Current Pediatric Therapy. 15th Ed. Edited by F Burg, J Ingelfinger, E Wald, and R Colin. (Pp 894; £55 hardback.) WB Saunders, 1996. ISBN 07216-5016-3.

Over the years successive editions of Gellis and Kagan's classic work, just like Topsy, have 'growed and growed'. Thirty years on and now in its 15th edition, this magnum opus has four editors and $\mathbf{4 3 5}$ contributors. It seemed a little incongruous (and more than a little overwhelming) for a single reader to comment on such a body of scholarship and, in an attempt to redress the numerical imbalance, I enlisted a handful of willing colleagues

to help me undertake the task! These included a couple of general paediatricians, one with an interest in rheumatology, a paediatric oncologist, and a senior registrar. We each chose relevant sections of the book to read. I then collected comments, allowed them to simmer for several weeks and finally tried to prepare a distillate which was representative of our views.

Firstly, the design characteristics of the book were appreciated; printing was clear subheadings stood out, tables were easily assimilated, and key references were appended after each author's contribution. Inevitably the style of the text was a little uneven with such a huge authorship but it was easy to find one's way around the volume. The book is truly comprehensive with sections on fetal and adolescent medicine, behavioural and social medicine, and balanced consideration is given to emergency management of acute disorders as well as long term management of chronic conditions. I failed to find guidance on one topic only-pain relief in the dying child.

The consensus view is that Gellis and Kagan is a good reference book for providing the historic perspective on treatment as well as current concepts, although precise practical advice on challenging problems is sometimes lacking.

It should be noted that despite our reservations, my willing helpers have extracted a promise that the copy of this book that we are allowed to keep as a reward for our labours is generally available !

GAYNOR F COLE Consultant paediatric neurologist

\section{Correction}

Byler-like familial cholestasis in an extended kindred

An error unfortunately occurred in this paper by Bourke et al (1996;75:223-7). A vertical line indicating descent of the father of the larger sibship and his sister, the mother of the smaller affected sibship, from the second consanguineous grandparental marriage was inadvertently omitted from figure 1 . The correct depiction of the figure is shown below.
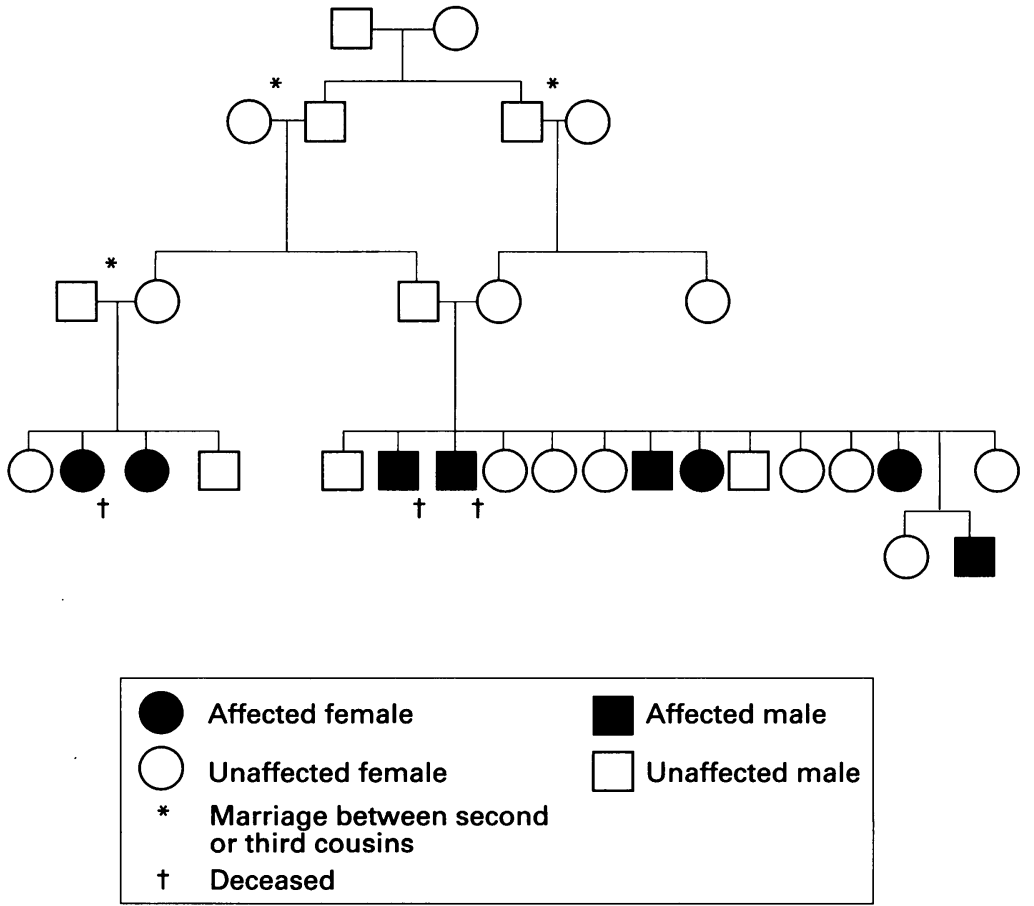

Figure 1 Pedigree of Irish Byler kindred illustrating high degree of intermarriage. 